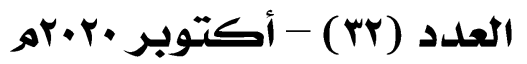

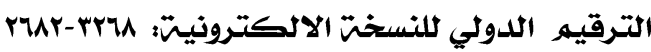

مجلت كلين التربيت - جامعت بوربعيل

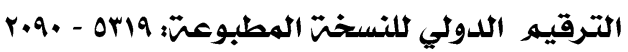

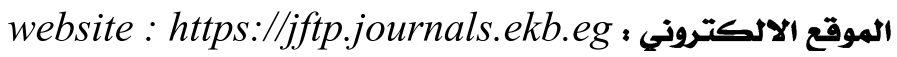

\title{
The Effectiveness of Personalized Learning Model in Developing Critical English Reading Skills among Preparatory Stage Pupils
}

\author{
Dr. Jehan Mahmoud \\ El-Bassuony
}

Professor of Curriculum \& (Instruction(EFL

Faculty of Education, Port

Said University

\author{
Dr. Mahmoud Mohamed \\ Mohaseb
}

Assistant Professor of Curriculum \& (Instruction (EFL

Faculty of Education, Port Said

\author{
Marwa Mahmoud \\ Mohamed Moussa \\ English Senior Teacher at Fatima \\ El-Zahraa Governmental \\ Language School
}

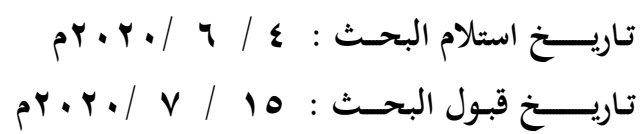

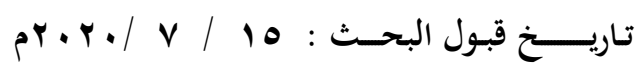

البريد الالكتروني للباحث : marwa105389@edu.psu.edu.eg

DOI: JFTP-2006-1048

Faculty of Education Journal - Port Said University

Printed ISSN : 2090-5319
V0I. (32) - October 2020

On Line ISSN : 2682-3268

website : https://jftp.journals.ekb.eg/ 
The Effectiveness of Personalized Learning Model in Developing Critical English Reading Skills among Preparatory Stage Pupils

Dr. Jehan El-Bassuony -Dr. Mahmoud Mohaseb - Marwa Moussa

\section{ABST'RACT}

The present study aimed at investigating the effectiveness of a Personalized Learning Model in developing intensive English reading skills. The quasi- experimental design was used. The participants were a sample of (57) second year preparatory stage pupils at Fatima Al-Zahraa Governmental Language School at Port Said. The researcher selected two classes; the first class of (29) learners as an experimental group and the second one of (28) learners as a control group. An intensive English reading skills questionnaire was prepared by the researcher to identify the different levels of importance of some intensive English reading skills necessary for the second year preparatory stage pupils . An intensive English reading skills test was designed by the researcher to be used as an instrument to assess the pupils' progress in intensive English reading skills. The experiment was applied during the first term of the academic year2019/2020.The data obtained from the study has been analyzed statistically by SPSS program. Research results revealed significant differences between the post-test mean scores of the experimental and control groups in the intensive English reading skills in favor of the experimental group.

\section{KEYWORDS:}

Intensive Reading, Personalized Learning, Preparatory Stage Pupils 
The Effectiveness of Personalized Learning Model in Developing Critical English Reading Skills among Preparatory Stage Pupils

Dr. Jehan El-Bassuony -Dr. Mahmoud Mohaseb - Marwa Moussa

\section{|ll|}

هدفت هذه الاراسة إلى التحقق من فاعلية نموذج التعلم الثخصى قى تنمية بعض مهارات

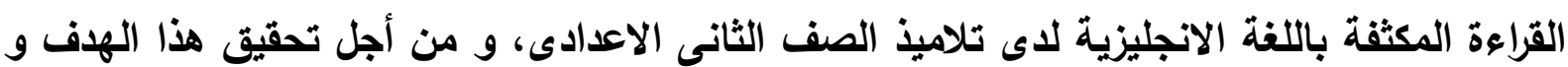

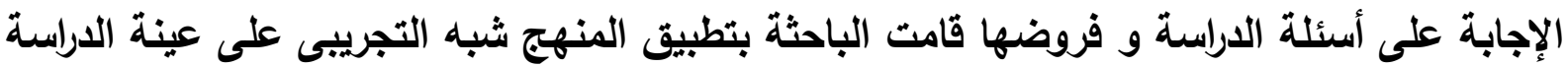
و المكونة من (هV ) تلميذا من تلاميذ مدرسة الزهراء الرسمية للغات ببورسعيد: مجموعة تجريبية

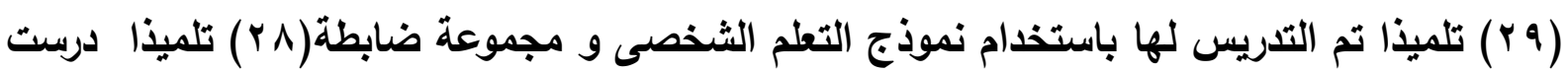

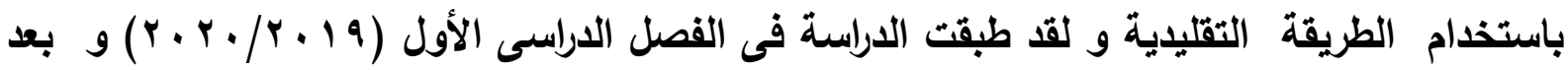

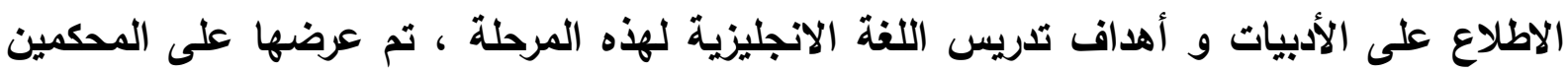

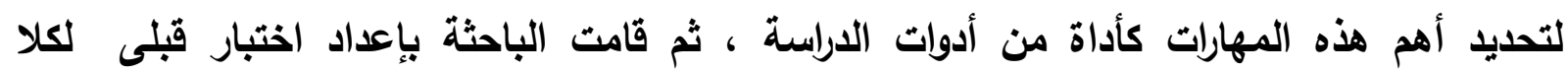

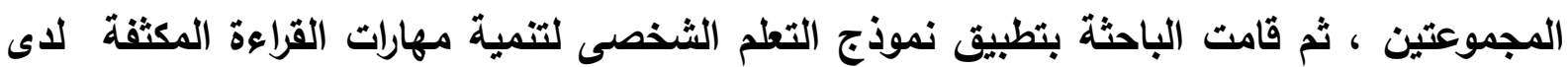
تلاميذ المرحلة الإعدادية على المجموعة التجريبية فى حين تلقت المجموعة الضابطة التعلم باستخدام

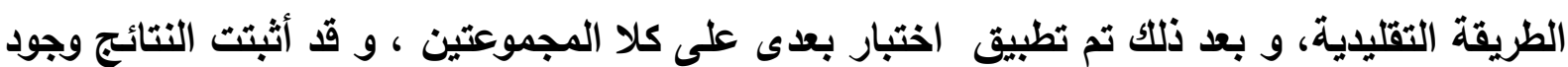

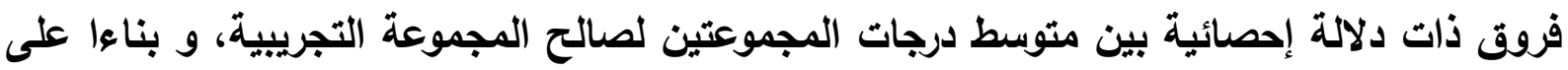
ذللك أثثتت النتائج فاعلية نموذج التعلم الثخصى فئ تنمية مهارات القراعة المكثفة لدى تلاميذ المرحلة الإعدادية.

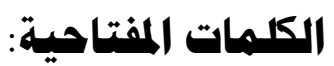

القراعةالمكثفة، نموذج التعلم الثخصى، تلاميذ المرحلة الإعدادية. 
The Effectiveness of Personalized Learning Model in Developing Critical English Reading Skills among Preparatory Stage Pupils

Dr. Jehan El-Bassuony -Dr. Mahmoud Mohaseb - Marwa Moussa

\section{Introduction}

Reading is classified a basic need in the modern world of science and technology. Reading is a key to success in school, to the development of outof-school interests, to the enjoyment of leisure time and to personal and social adjustment .Through reading someone acquires many of his/her standards of behavior and morality, broadens his/her interests, tastes and understanding of others. Effective reading is the most important avenue to effective learning. Reading is so interrelated with the total educational process that educational success requires successful reading. Although it is important to read, students are automatically moved to the next level of automatic promotion regardless of their performance. Automatic promotion is a system of promoting learners through the school system ,regardless of their level of performance in reading (Hartney, 2011: 18-20).

Also, reading, either first or second/foreign language has been a social, complex and interactive process which every person must go through almost every day for various reasons. One of the most general reasons for reading may be the need to be a part of a particular society. Members of any society need to cope with the demands of the society and keep up with it as well. The most basic requirement of most of the societies has always been to enroll in a school whose first function is to teach and promote literacy among its members (Balikci, 2012: 1-2).

Although reading a text could be informative and interesting, instead it can become a struggle, so teachers need to provide consistent intervention and support to help students make meaning from what can seem to them like a meaningless text. Further, a text that is difficult for students to read may lower their confidence and motivation not just for reading in an L2, but for language learning in general. As a result, intensive-reading tasks are used to motivate students to read those seemingly difficult texts (Warfield, 2019: 31).

Intensive reading refers to reading short texts thoroughly and with clear objectives, such as to answer reading comprehension questions or to identify how sentences are linked. Unlike extensive reading, the goal of intensive reading is not to read many texts for fluency, but rather to read a shorter piece of text to gain a deeper understanding of that text. Although reading comprehension can be one goal of intensive reading, its goals may include learning subject matter, vocabulary learning and studying the authors' intentions. In other words, the goal of intensive reading is not limited to reading comprehension (Koay, 2016).

Shanahan (2018) clarifies that to raise reading achievement, there is no point to teaching most comprehension skills. On the other hand, there are 
The Effectiveness of Personalized Learning Model in Developing Critical English Reading Skills among Preparatory Stage Pupils

Dr. Jehan El-Bassuony -Dr. Mahmoud Mohaseb - Marwa Moussa

very good reasons for teaching comprehension strategies. In addition , he assures that comprehension skills and comprehension strategies are very different things. Basically, the term comprehension skills tend to refer to the abilities required to answer particular kinds of comprehension questions. Skills would include things like identifying the main idea, supporting details, drawing conclusions, inferencing, comparing and contrasting, evaluating critically, knowing vocabulary meaning, and sequencing events. Whereas, comprehension strategies are described as actions that are used intentionally by readers to increase the chances of understanding or remembering what one has read.

As a result, in intensive reading activities, learners are highly exposed to relatively short texts which are used either to exemplify specific aspects of the lexical, syntactic or discoursal system of the L2, or to provide the basis for targeted reading strategy practice; the goal of extensive reading, on the other hand, is to 'flood' learners with large quantities of L2 input with few or possibly no specific tasks to perform on this material (Alyousef, 2005: 147).

Personalized learning is an emerging trend which seeks to support student-centered, 21st century teaching and learning. A growing body of research suggests that that overall student achievement is likely to increase when students are able to learn at their own pace with a variety of teaching styles and formats available to them. The needs of students are put first and students are able to direct how, what, when, and where they learn (Hanover Research, 2012: 4).

Also, Dada (2015) and Demski (2012) agree that personalized learning is defined as a student- centered teaching and learning model that acknowledges and accommodates the range of abilities, prior experiences, needs, and interests of each student, with the goal of moving every student to a higher standard of achievement.

Bray and McClaskey( 2013: 13) differentiate among the following three terms:

Personalization: Instruction is paced to learning needs, tailored to learning preferences, and tailored to the specific interests of different learners. Differentiation :Instruction is tailored to the learning preferences of different learners.

Individualization: Instruction is paced to the learning needs of different learners

In their study, Gradu and Kuutila (2016: 8-9) explained that the key difference between the personalized learning approach, the differentiation and individualization is the students' role in the personalization process. In differentiation and individualization the analysis and decision making 
The Effectiveness of Personalized Learning Model in Developing Critical English Reading Skills among Preparatory Stage Pupils

Dr. Jehan El-Bassuony -Dr. Mahmoud Mohaseb - Marwa Moussa

would seem to be mostly in the hands of the teacher, whereas in personalization one of the most crucial points is that

learners begin to take responsibility for and ownership of their own learning.

Wolf (2010:7) illustrates that the basic principles on which the personalized learning model depends on are as the following:

1- Each learner is unique and learns in different ways. It determines how the student learns better.

2- PL directs and organizes the learner self-help and helps in the design of the course of learning, showing the student's voice and selection in the learning process.

3 - It makes it a common designer in the curriculum and the learning environment, and learners become the partners of teachers in the learning process.

4 - PL also gives the flexibility of learning is at any time and anywhere Identify students for their own learning goals .

5- It manages the learning process in terms of content and mechanisms alike .

6 - PL makes learners communicate with others during the learning process.

Personalization encourages educators to be more open and flexible, so that students can become more invested in designing their own personal learning paths. Students engaged in personalized learning at their various paces are given access to tools and feedback that motivate them to capitalize on their unique skills and potential. Personalization empowers students to take true ownership of their education, altering the dynamic between teachers and students. is new model gives teachers the time and information they need to design personalized instruction that builds the critical thinking skills crucial to independent learning. Teachers can also create diverse, highly personalized learning environments that recognize students' different skills, challenges, and talents (Grant \& Basye, 2014:1-2).

Thus, Personalized Learning Model involves several aspects of competencies like Cognitive competency-what we know; prior knowledge which facilitates new learning, broad knowledge acquired in any context, accessible in memory to facilitate new learning, sufficient depth of understanding to expedite acquisition of new learning. Metacognitive competency-how we learn; self-regulation of learning and use of learning strategies. Motivational competency—why we learn; engagement and persistence in pursuit of learning goals and Social/Emotional competency-who we are; sense of self-worth, regard for others, emotional understanding and management, ability to set positive goals and make responsible decisions (Redding, 2016:7). 
The Effectiveness of Personalized Learning Model in Developing Critical English Reading Skills among Preparatory Stage Pupils

Dr. Jehan El-Bassuony -Dr. Mahmoud Mohaseb - Marwa Moussa

As cited in Dag and Gecer (2009: 863), Akkoyunlu (1995) is

pointed out that determination of the learner's learning styles can assist to teachers for the matter is that a method how to develop in teaching process. Determination of the learner's learning styles is a benefit in terms of the learners, also. Therefore, if the learners have knowledge of their learning styles, in the learning process, they can see their weak and strong sides in regard to their learning and they can tend to suitable learning environment and learn knowledge easily and permanently, also. Learning styles aim personalization of the learning by finding of clues with regard to their learning and to establish a ground to each learner to study by individually or in small groups.

Personalized learning has the potential to revolutionize the education system. Nonetheless, without guidance or research-based understanding, personalized learning will be haphazardly referenced, partially implemented, eventually demonized, and then viewed as an unrealistic fad in education (A Guide for Implementing Personalized Student Learning Plan (PSLP) Programs, 2014:2).

Jenkins and Kelly (2016:1-8) considered the most common challenge of teachers, school leaders and districts leaders alike was "buyin" which is defined as getting your team or organization to understand, support and align on a unified approach and absorb vision for this work and a clear plan on how do it .While the second most common challenge for district leaders and teachers was support and training, school leaders stated they struggle the most with implementation. District leaders must design the overarching district plan of support and professional development; teachers are worried about receiving that adequate support and training. Principals, as the site leaders and intermediaries between teachers and the district, have to carry out the district plans and make sure that teacher needs are met.

Personalized learning environments require more than technology, that the technology itself is simply a tool to support implementation ( Basham, Hall, Carter JR \& Stahl 2016: 1-7 ). Student customization represents an important advance because it recognizes that pupils come from different backgrounds, interests, and ability levels. Chris Rush, the cofounder of the school, argues that the key cultural mindset that changes with School of One is not the technology, but the way in which the program thinks about student progress (West, 2011:4).

An example that supports that idea, Kevin McLaughlin, a primary teacher at Old Mill Primary School in Leicestershire, England. He divided his classroom into five zones to enable learners to approach and respond to concepts on their own terms. This is how he laid out his learning environment. To begin redesigning the learning environment to support 
The Effectiveness of Personalized Learning Model in Developing Critical English Reading Skills among Preparatory Stage Pupils

Dr. Jehan El-Bassuony -Dr. Mahmoud Mohaseb - Marwa Moussa

how learners learn best, including these FIVE zones of personalized learning model :

1. Discussion and Thinking Zone: Learners participate in whole- class discussion and ask about their learning.

2. Discovery Zone : Learners investigate and solve problems and collaborate on projects.

3. Show-Off Zone: Learners write, present and share their work .

4. Repeat Zone : Learners come here when they need help, advice and explanation .

5. Creation Zone: Learners write, edit,develop and refine their content presentation (Bray \& McClaskey, 2013: 17).

Figure (1) Kevin McLaughlin's Five Zones of Personalized Learning

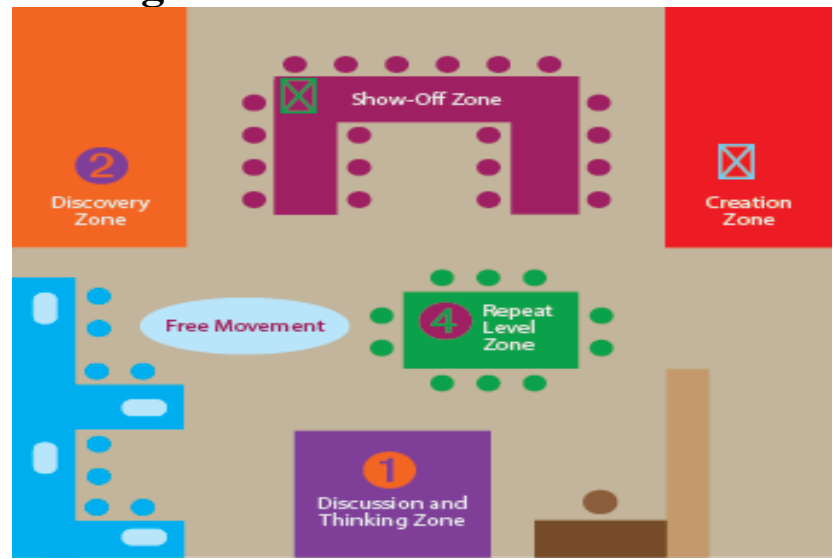

Source: Bray and McClaskey (2013:17)

Technology-rich environments, of course, offer greater potential for the design of instruction based on personal information provided by the target audience. Students and trainees in high-technology settings can enter their relevant personal information (e.g., interests, department or type of job, preferred learning structure) into a general database or one created for a particular instructional or training unit. This information can be incorporated directly into computer based instruction, computer-based training, or on-line learning to personalize the instruction for each individual or for groups based on factors such as their common interests, work responsibilities, or instructional preferences (Yu Ku: 33 ).

Based on the personal learning environment that is considered as a system that helps learners to control and manage their learning process and the tools needed to create personal learning environments:

- Website images such as Flicker

- The site of the video and the most famous site YouTube

- Blogs such as Blogger

- Wiki like Wikipedia and others 
The Effectiveness of Personalized Learning Model in Developing Critical English Reading Skills among Preparatory Stage Pupils

Dr. Jehan El-Bassuony -Dr. Mahmoud Mohaseb - Marwa Moussa

- Social communication tools are services that help connect people to each other to share experiences and information such as facebook (Hijazy, 2018) .

Studies Related to Personalized Learning

Svenningsen and Pear (2011) conducted two experiments to assess an online version of Keller's personalized system of instruction, called computer- aided personalized system of instruction (CAPSI), as part of a blended learning design with regard to course knowledge and critical thinking development. The finding revealed improvement of higher-order thinking skills in students enrolled in PSI courses.

Moreover, Asztalos (2014) aimed at exploring the potential of the wiki as a platform for knowledge building and PL that may enhance lifelong learning and students' self-regulation. Individual learning paths were encouraged by the introduction of a personalized evaluation system, in which points were given for any task the students had completed. The finding proved that that students' perceived language development increased, while their disposition towards the wiki and the personalized evaluation system became more positive by the end of the project suggests that the successful implementation of a new tool not only needs utmost care and planning but also a considerable amount of time.

Furthermore, Koller (2015) built his study on personalized vocabulary learning plan (PVP). The conclusion revealed that it was a useful tool in developing learner autonomy when used for planning, student-teacher collaboration and reflective practices and confirmed that one way to encourage learners to become more autonomous is to increase their confidence in their own abilities.

Basham et al., (2016) sought to develop a better understanding of K12 personalized learning environments. Findings indicated that personalized learning environments require more than technology, that the technology itself is simply a tool to support implementation. These personalized learning environments were highly learner self-regulated, had transparent and actionable near-real-time data, provided various structures for student voice and feedback, and integrated purposeful supports for embedding the principles of Universal Design for Learning at the cornerstone of practice.

Also, Gradu and Kuutila (2016) pointed out countless ways that underlying ideas of PL that can be transformed into action and by making education more humane process by looking at how five teachers had implemented the approach that consisted of the following concepts: (1) small-group learning, (2) flipped learning, (3) blended learning, (4) mastery learning, and (5) self-paced learning. Clearly, All of the participants used some form of small group learning, even though it manifested in various 
The Effectiveness of Personalized Learning Model in Developing Critical English Reading Skills among Preparatory Stage Pupils

Dr. Jehan El-Bassuony -Dr. Mahmoud Mohaseb - Marwa Moussa

ways. Assessment practices were varied in the implementations, Johanna's being the most conventional with a strong emphasis on traditional testing. Smaller summative tests and actual oral tests were reportedly only used by Anneli, whereas Minna used small tests purely for formative purposes. Assessment discussions were used by Minna and Maria, whereas self-assessments were used by Minna, Maria and Helena.

Dinkins's study (2017) explored teachers' perceptions of implementing PL in several urban elementary school classrooms. While teachers felt they had the resources needed to implement personalized learning and were empowered to make decisions about the implementation process, they did not feel they had sufficient knowledge and skills to implement the approach.

Zou and Xie's study (2018) showed that e-learning systems should be designed based on comprehensive learning theories, so the researchers develop such a system. This system recommends personalized word learning tasks based on the technique feature analysis scores of different tasks and user models through three approaches: a non-personalized approach, a personalized approach guided by a partial version of the technique feature analysis, and a personalized approach guided by the full list of the technique feature analysis, with the personalized approach guided by the complete checklist leading to the best learning performance.

\section{Context of the Problem}

As an English senior teacher, the researcher observed the weak level of some intensive reading skills among the preparatory stage pupils and they moved to the next grade regardless their performance. In addition, her discussion with colleagues and expert supervisors revealed that they shared the same opinion.

The Pilot Study

Empirically, a pilot study was conducted to assess the second preparatory stage pupils' EFL intensive reading skills. An intensive English reading test was designed and applied to a group of the second preparatory stage pupils $(\mathrm{N}=25)$. The test consisted of a text of 10 questions. The results of the test indicated the apparent inefficiency of intensive English reading skills for EFL preparatory stage pupils as revealed by their low scores.

\section{Statement of the problem}

Based on the previous studies and the results of the pilot study, the problem of the study can be identified in poor mastery of intensive reading skills among second year preparatory pupils. The current study attempted to investigate the effectiveness of the personalized learning model in developing second year preparatory stage pupils' EFL intensive reading 
The Effectiveness of Personalized Learning Model in Developing Critical English Reading Skills among Preparatory Stage Pupils

Dr. Jehan El-Bassuony -Dr. Mahmoud Mohaseb - Marwa Moussa

skills. Therefore, the present study sought to find an answer to the following main question:

What is the effectiveness of the Personalized Learning Model (PLM) in developing some intensive English reading skills of preparatory stage pupils?

More specifically, the study investigated the following sub-questions:

1 - What are the intensive reading skills required for second year preparatory stage pupils?

2- What are the features of a treatment based on the PLM to develop intensive reading skills of the second year preparatory Stage pupils'?

3- To what extent does the PLM enhance preparatory stage pupils' intensive reading skills?

\section{Hypotheses of the Study}

To answer the questions of the study, the researcher posited the following hypotheses:

1-There is a statistically significant difference between the mean scores of the experimental group and the control one on the overall post intensive reading skills test in favour of the former.

2-There are statistically significant differences between the mean scores of the control and experimental groups on the post intensive reading skills test for the sub skills in favour of the latter.

Significance of the Study

The present study derived its significance from the following considerations:

For Curriculum Designers/ Planners

The study can provide some guidelines based on the Personalized Learning Model for curriculum designers in developing intensive English reading skills. Also, the proposed model can be used to develop the other English skills(listening, speaking and writing).

For Teachers and researchers

The current study provides an empirical evidence for teachers about the steps of using the Personalized Learning Model to develop intensive English reading skills.

For Pupils

The model can contribute in engaging all pupils without exception in the learning process. It helps pupils in developing the ability to generate questions and solve everyday problems as it increases the self-confidence of learners and enhances motivation and independence so that learners can begin to take responsibility and ownership of their learning.

Delimitations of the study

The present study was limited to : 
The Effectiveness of Personalized Learning Model in Developing Critical English Reading Skills among Preparatory Stage Pupils

Dr. Jehan El-Bassuony -Dr. Mahmoud Mohaseb - Marwa Moussa

- The participants were 57 pupils registered in the second year

preparatory stage of the academic year 2019-2020 in El- Zahraa Governmental Language School in Port Said.

- Intensive reading skills that were appropriate to the second year preparatory stage pupils were selected.

-The study took place in El- Zahraa Governmental Language School . It was conducted during the English language periods at school. The experiment lasted for eight weeks, two periods per week. It began on 25/9/2019 and ended on 11/12/ 2019.

Design of the Study

The design of the study was the quasi - experimental . Two intact groups of second year preparatory stage pupils at Fatima El-Zahraa Governmental School at Port Said were selected .They represented a control group and an experimental one. The experimental group received treatment through sessions that were designed according to the Personalized Learning Model to develop intensive English reading skills. On the other hand, the control group received treatment through regular instruction.

A test was given to both groups before and after the implementing of the Personalized Learning Model. The experimental group's mean score was compared to the control group's mean score on the post test to measure the effectiveness of using the Personalized Learning Model in developing intensive English reading skills.

Drawing on the main aim of the study, the experiment was conducted targeting one independent variable and one dependent variable. The Personalized Learning Model is the independent variable, whereas intensive English reading skills represent the dependent variable.

Instruments of the Study

The present study included the following instruments :

1-The Intensive English Reading Skills Questionnaire

2-The Pre-Post Intensive English Reading Skills Test

\section{1-The Intensive English Reading Skills Questionnaire}

The aim of this questionnaire was to determine the most important intensive English reading skills necessary for the targeted pupils ( EFL second grade Fatima El-zahraa Governmental Language School preparatory stage pupils) in order to develop intensive reading skills by using the Personalized Learning Model.

The questionnaire consisted of 19 items: read a text for(a ) general idea (s),read a text for specific information, identify related ideas in a text, Recognize cause and effect relationship, determine sequence of events ,briefing text ideas, rephrase a text, identify the author's implicit 
The Effectiveness of Personalized Learning Model in Developing Critical English Reading Skills among Preparatory Stage Pupils

Dr. Jehan El-Bassuony -Dr. Mahmoud Mohaseb - Marwa Moussa

purpose, identify sub ideas in a text, identify contrasted ideas,

differentiate between facts and opinions, distinguish between reality and virtuality, identify references, make inferences and detect the author's attitude(s), judge suitability of decisions, detect moral values and/ or lessons, detect problems and solutions and estimate arguments strength .

validity of the questionnaire

1-The researcher prepared a preliminary questionnaire of intensive English reading skills required for Fatima El-zahraa Governmental Language School preparatory stage pupils.

2- To judge the validity of the questionnaire, it was submitted to a panel of jury specialized in the field of EFL Curriculum and Instruction $(N=20)$ to determine the degree of importance(very important, important or less important) of each skill and its appropriateness to the purpose of the study. The jury members were asked to add, modify or omit any intensive English reading skills and give comments. The previous suggestions and modifications were taken into consideration when editing the selected or the final version of the intensive reading skills questionnaire.

The English language experts agreed upon the importance of the selected intensive reading skills as follows:

Detect moral values and/ or lessons $\wedge_{\diamond \%}$, Judge suitability of decisions $75 \%$ Read a text for (a) general idea(s) 70\%, Detect the author's attitude(s) $70 \%$, according to collecting the percentage of the importance for each sub skill that ranged between important and very important.

\section{2-The Pre-Post Intensive English Reading Skills Test}

The major aim of the intensive English reading skills test was to investigate the effectiveness of the personalized learning model in developing some intensive English reading skills for second year prep school pupils.

The researcher prepared the test in its initial form (10) questions to a number of specialized experts in curriculum and methods of teaching English to determine the suitability of the questions to measure the intensive English reading skills for the second preparatory pupils. They agreed on the validity of the questions to measure intensive English reading skills, and the final version of the test was modified according to the feedback given by the jury members. The test included four questions based on the selected intensive English reading skills. The intensive English reading skills test was designed to measure the following four intensive English reading skills that were selected by the jury: read a text for a general idea(s), detect the author's attitude(s), judge suitability of decisions, and detect moral values and/ or lessons.

Test Validity 
The Effectiveness of Personalized Learning Model in Developing Critical English Reading Skills among Preparatory Stage Pupils

Dr. Jehan El-Bassuony -Dr. Mahmoud Mohaseb - Marwa Moussa

The researcher used two methods to prove the validity of the test as follows:

\section{A-Jurors' Validity}

The researcher presented the test in its initial form (10) questions to a number of specialized experts in curricula and methods of teaching English to determine the suitability of the questions to measure the intensive English reading skills for the second preparatory pupils. They agreed on the validity of the questions to measure intensive English reading skills. The final version of the test was modified according to the feedback given by the jury members. The test included four questions based on the most important four intensive English reading skills.

B- Internal Consistency

The intrinsic validity of the test was calculated by using Pearson Correlation coefficient. The correlation coefficients between the English language skills and the overall English language skills test are significant at (0.01) for question four and significant at $(0.05)$ for questions one, two and three.

\section{Reliability of the Test}

In order to measure the reliability of the test, both Test-Retest and Half-Split were used as the following :

Test - Retest

The researcher calculated the reliability of the test by retesting the test sample $(\mathbf{N}=25)$ at an interval of about fifteen days. The correlation coefficient between the first and second administration scores was $(\cdot v \bullet r)$, statistically significant at the level of $(0.01)$ which indicates that the test has an appropriate degree of reliability.

Difficulty Coefficient

The difficulty coefficient varied between $(0.40$ - 0.72$)$, thus all the items were acceptable or in the normal limit of difficulties.

Table (1) Difficulty and Ease Coefficient of the Test Items

\begin{tabular}{|c|c|l|l|l|}
\hline Item No & $\begin{array}{l}\text { Correct } \\
\text { Answers }\end{array}$ & $\begin{array}{l}\text { Wrong } \\
\text { Answers }\end{array}$ & $\begin{array}{l}\text { Difficulty } \\
\text { Coefficient }\end{array}$ & $\begin{array}{l}\text { Ease } \\
\text { Coefficient }\end{array}$ \\
\hline 1 & 13 & 12 & 0.48 & 0.52 \\
\hline 2 & 7 & 18 & 0.72 & 0.28 \\
\hline 3 & 13 & 12 & 0.48 & 0.52 \\
\hline 4 & 9 & 16 & 0.64 & 0.36 \\
\hline
\end{tabular}

Analyzing the Results of Study Hypotheses 
The Effectiveness of Personalized Learning Model in Developing Critical English Reading Skills among Preparatory Stage Pupils

Dr. Jehan El-Bassuony -Dr. Mahmoud Mohaseb - Marwa Moussa

The main purpose of the present study was to investigate the effectiveness of Personalized Learning Model in developing the intensive English reading skills of preparatory school stage pupils.The results of the study proved that " There is a statistically significant difference between the mean scores of the experimental group and the control one on the overall post intensive reading skills test in favour of the former.".In addition, "There are statistically significant differences between the mean scores of the control and experimental groups on the post intensive reading skills test for the sub skills in favor of the latter."

The First Hypothesis

To verify the first hypothesis, which states:"There is a statistically significant difference between the mean scores of the experimental group and the control one on the overall post intensive reading skills test in favour of the former.", t-test was conducted on both the experimental and control groups' scores in the intensive reading skills post test to determine the relative extent of change achieved by the experimental group after implementing the sessions that are based on PLM.

Table (2) Comparison of the experimental group and the control group on the overall mean score of the post-test

\begin{tabular}{|c|c|c|c|c|c|c|c|c|}
\hline \multirow{4}{*}{ Total } & \multicolumn{8}{|c|}{ Groups } \\
\hline & \multicolumn{3}{|c|}{ Control Group } & \multicolumn{3}{|c|}{ Experimental Group } & \multirow{2}{*}{$\begin{array}{l}\text { T-test } \\
\text { value }\end{array}$} & \multirow{2}{*}{$\begin{array}{l}\text { Sign. } \\
\text { level }\end{array}$} \\
\hline & $\mathbf{N}$ & Mean & SD & $\mathbf{N}$ & Mean & SD & & \\
\hline & 28 & 2.9 & 1.2 & 29 & 6.2 & 1.2 & 10.6 & 0.01 \\
\hline
\end{tabular}

Results in table (2) show that there is significant statistical difference between the mean scores of the experimental and those of the control group on the post intensive reading skills in favour of the scores of the former. This indicates that the experimental group scored higher on the intensive English reading skills post-test than the scores of the control group. The ttest results show that this difference is considered to be highly statistically significant at $(\cdot \cdot 1)$ level. The interpretation of this difference proves that the intensive reading skills of the experimental group who implemented PLM have been improved. This confirms the positive effect of PLM in developing their intensive reading skills. Therefore, the first hypothesis of the study is supported.

\section{The Second Hypothesis}

In order to verify the second hypothesis, which states: "There are statistically significant differences between the mean scores of the control and experimental groups on the post intensive reading skills test for the sub skills in favor of the latter.", t-test was conducted on both the 
The Effectiveness of Personalized Learning Model in Developing Critical English Reading Skills among Preparatory Stage Pupils

Dr. Jehan El-Bassuony -Dr. Mahmoud Mohaseb - Marwa Moussa

experimental and the control to determine the relative extent of change achieved by the experimental group after implementing PLM.

Table(3) Comparison of the experimental group and the control group on the mean scores of the sub skills on the post -test

\begin{tabular}{|c|c|c|c|c|c|c|c|c|}
\hline Skills & \multicolumn{6}{|c|}{ Groups } & \multirow{2}{*}{$\begin{array}{l}\text { t-test } \\
\text { value }\end{array}$} & \multirow{2}{*}{$\begin{array}{l}\text { Sign. } \\
\text { level }\end{array}$} \\
\hline & \multicolumn{3}{|c|}{ Control Group } & \multicolumn{3}{|c|}{ Experimental Group } & & \\
\hline & $\mathbf{N}$ & Mean & SD & $\mathbf{N}$ & Mean & SD & & \\
\hline $\begin{array}{c}\text { 1-Read a text for (a ) } \\
\text { general idea (s) }\end{array}$ & 28 & $\cdot .11$ &. .0 . & 29 & $\cdot 94$ & דצ'. & r.1 & $\because \cdot 1$ \\
\hline B-Scanning & & & & & & & & \\
\hline $\begin{array}{c}\text { 2-Detect the } \\
\text { author's attitude(s) }\end{array}$ & 28 & $\cdot .39$ & .0 . & 29 & $\cdot \wedge r$ & $\cdot r \wedge$ & $r . v$ & $\because \cdot 1$ \\
\hline $\begin{array}{l}\text { 3-Judge suitability } \\
\text { of decisions }\end{array}$ & 28 & $\cdot r 2$ & 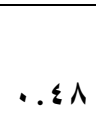 & 29 & $\because \wedge 7$ & or & $\varepsilon .9$ & $\because 1$ \\
\hline $\begin{array}{l}\text { 4-Detect moral } \\
\text { values and/ or } \\
\text { lessons }\end{array}$ & 28 & $\cdot r 2$ & $\because \leqslant \Lambda$ & 29 & $\cdot v 9$ & $\because \leqslant 1$ & ؛ & $\because 1$ \\
\hline Total & r8 & 1.7 & .90 & 29 & r. & r. & A.r & 0.01 \\
\hline
\end{tabular}

Figure(2) Comparison of the experimental group and the control group on the mean scores of the sub skills on the post -test

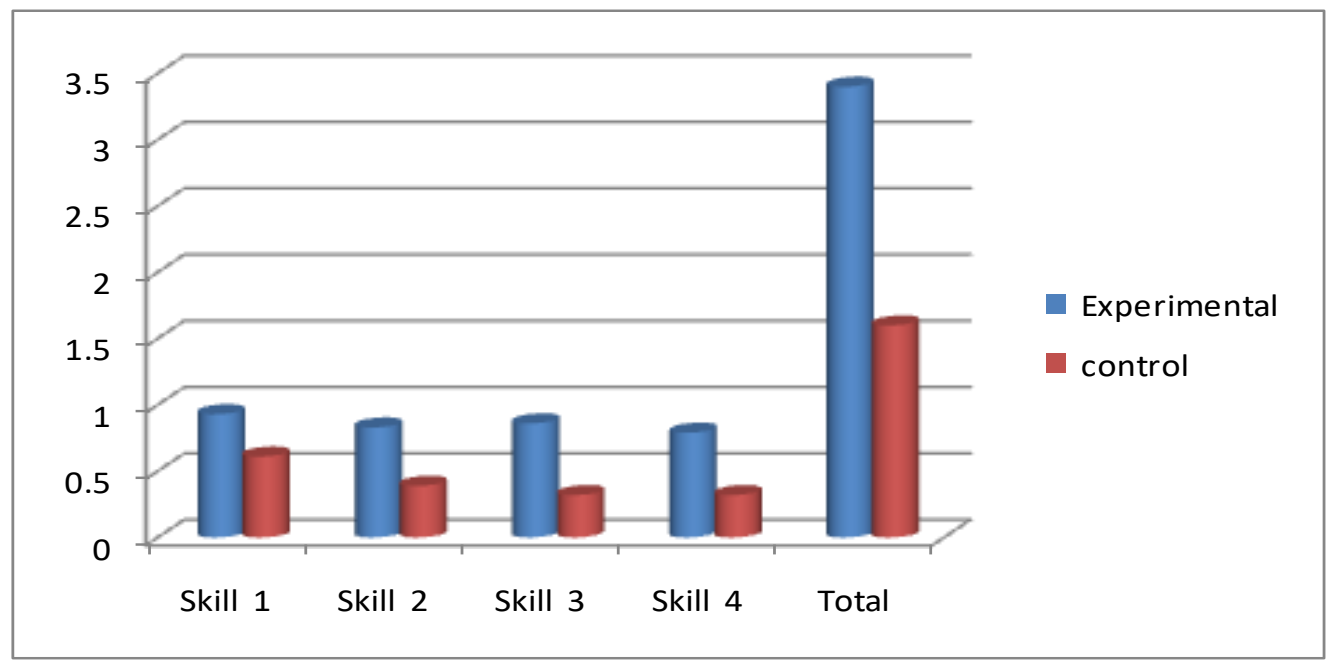

Results in table (3) and figure (2) show that There are statistically significant differences between the mean scores of the control and experimental groups on the post intensive reading skills test for the sub skills in favor of the latter. This indicates that the experimental group scored higher on the intensive reading skills post-test, on the sub skills 
The Effectiveness of Personalized Learning Model in Developing Critical English Reading Skills among Preparatory Stage Pupils

Dr. Jehan El-Bassuony -Dr. Mahmoud Mohaseb - Marwa Moussa

than the scores on the intensive reading skills post- test of the control group .The t-test results show that this difference is considered to be highly statistically significant at $(0.01)$ level. The interpretation of this difference proves that the intensive English reading skills of the pupils who participated in PLM have been improved. This confirms the positive effect of PLM on developing the intensive reading skills. Therefore, the second hypothesis of his study is supported.

\section{Discussion}

The experimental group pupils' progress was due to the following:

a) Applying Personalized Learning Model zones helped pupils achieve their purposes in all cases, they could cooperate and design an activity that touched their needs and interests individually, in pairs or in groups: (collecting pictures, gathering information , arranging ideas, typing, editing videos, surfing the internet and so on ), so pupils acquired more basic regulated skills in addition to developing their creative English reading skills . Also, some pupils who did not dare to stand up and say just a word in English before applying PLM became active pupils. They planned for the sessions from $A$ to $Z$ so that they could write down a script with suitable music and movements used in the sessions .

b) The pupils used their personal profiles based on UDL that discover their interests, needs and competencies. Pupils were interested in what they were going to do through PLM zones because all of them without exception participated through their specific sectors even who needed help asked without being hesitant or shy because of their right to use "Repeat Zone" if necessary. The content was more simple and practical through preclassroom activities, during classroom activities and post - classroom activities."

c) It is worthwhile to mention that creating a cooperative and social environment during implementing PLM participated in developing critical reading skills. Providing other: "by product" results, such as self confidence by engaging pupils to work in pairs and groups even pupils who worked individually in doing activities could participate cooperatively through PLM with its zones in which s/he wrote their names and participation in the Placemat Consensus Sheet to enhance some grammatical items and improve memorization to be more autonomous. This result goes along with the study conducted by Koller (2015).

d) PLM is considered the cornerstone of enhancing the pupils' unique fingerprints. It enhanced their personal voices and choices in learning through addressing all pupils' learning styles, it made them felt satisfied from the very beginning to the end of learning process because they were motivated enough to find good reasons for their learning according to the pupils' competencies: cognitive, metacognitive, motivational and social. 
The Effectiveness of Personalized Learning Model in Developing Critical English Reading Skills among Preparatory Stage Pupils

Dr. Jehan El-Bassuony -Dr. Mahmoud Mohaseb - Marwa Moussa

e) Using PLM gave a transparent assessment for every step for all the pupils .They assessed themselves honestly during the learning journey because even trouble maker and shy pupils were satisfied because no one failed because they found the activities were suitable for their competencies (cognitive, metacognitive, motivational and social).

f) Using technology during applying Personalized Learning Model/zones was not the distinctive point because Personalized Learning Model/ zones could stand alone, but using technology could support all learning styles of pupils in the globalization era . Using technology saved $\mathrm{g}$ much time. Also, it increased social relationship among pupils because they met together to agreed upon a plan for their tasks in an activity inside and outside their classroom even through a phone call outside school. This result is consistent with Basham et al., (2016) and Asztalos (2014).

g) Moreover, following specific steps during presenting the sessions was considered a very important feature of the personalized learning model, these steps made learners follow logical steps that could be flexible according to the learning situations to be more reflective, decision makers. This result is in accordance with the results of the study conducted by Gradu and Kuutila (2016).

h) Moreover, following specific steps during presenting the sessions that parallel to the assessment is considered a very important feature of the personalized learning model, these steps made learners follow logical steps that can be flexible according to the learning situations to be more reflective, decision makers. This result is in accordance with the results of the e study conducted by Gradu and Kuutila (2016).

i) As a result, pupils reached autonomy that could create mastery, they became more active, autonomous, reflective, cooperative, self regulated, self confident, responsible, good researcher for information with or without using technology.

\section{Conclusion}

The main purpose of the present study was to investigate the effectiveness of the personalized learning model in developing the intensive reading skills of the second preparatory stage pupils. The results of the study proved the following:

1- Personalized Learning Model was better than the regular method on developing intensive reading skills.

2- There is a statistically significant difference between the mean scores of the experimental group and the control one on the overall post intensive reading skills test in favour of the former.

3- There are statistically significant differences between the mean scores of the control and experimental groups on the post intensive reading skills test for the sub skills in favor of the latter. 
The Effectiveness of Personalized Learning Model in Developing Critical English Reading Skills among Preparatory Stage Pupils

Dr. Jehan El-Bassuony -Dr. Mahmoud Mohaseb - Marwa Moussa

4-The proposed treatment was found to address ODL which enhanced the pupils four competencies: (cognitive, motivational (effective), metacognitive( psychomotor) and social.

5-The was consistency between teachers' lesson plan and the actual performance of the teacher and pupils in the classroom.

6-The participants in the experimental group felt more comfortable , confident, self regulated and autonomous to achieve all steps for preparing a lesson even preparing for movements required in some sessions related to health or selecting suitable music for editing some videos that were pupils' own activities.

Based on the obtained results of the present study, it was concluded that Personalized Learning Model was effective. For this reason, the study joins and adds to the validity of other studies that can investigate similar approaches to develop a variety of skills.

To conclude, discussing the obtained results of this study revealed that they were in line with those of related studies and supported by certain theoretical background that gives more importance to the necessity of acquiring EFL intensive reading skills according to the pupils' personal profile (UDL). Thus, PLM proved effectiveness in developing intensive reading skills. Besides, it made pupils go beyond the limits of the textbook and the walls of classrooms through various activities which enabled them to read the texts intensively.

Thus, PLM involves several aspects of competencies like Cognitive competency-what we know; prior knowledge which facilitates new learning, broad knowledge acquired in any context, accessible in memory to facilitate new learning, sufficient depth of understanding to expedite acquisition of new learning. Metacognitive competency-how we learn; self-regulation of learning and use of learning strategies. Motivational competency-why we learn; engagement and persistence in pursuit of learning goals and Social/Emotional competency-who we are; sense of self-worth, regard for others, emotional understanding and management, ability to set positive goals and make responsible decisions. (Redding, 2016:7).

As a result of the previous, pupils reach autonomy that can lead them to mastery, they can be active, autonomous, reflective, cooperative, self regulated, self confident, responsible, good researcher for information with or without using technology.

Suggestions for Further Research

Further research is needed to:

* apply the Personalized Learning Model for other English language skills to improve learning English language. 
The Effectiveness of Personalized Learning Model in Developing Critical English Reading Skills among Preparatory Stage Pupils

Dr. Jehan El-Bassuony -Dr. Mahmoud Mohaseb - Marwa Moussa

suggest the proposed model on students at other stages rather than preparatory stage.

* Develop other critical reading skills among learners in different stages.

* Use other tools of Personalized Learning in Egyptian schools at various stages, these tools can be as follows:

-Reading: Good Reader, Voice Dream, SpeakSelection

-Writing: Storykit, Dragon Dictation, Book Creator

-Collaborating: Skype, Screenchomp, GoDocs

-Organizing: DropBox, iHomework, Toodledoo

-Researching: Dragon Go, Qwiki, WolframAlpha

-Presenting: Prezi, iMovie, Keynote, Educreations (Bray and McClaske, 2013:5-9)

* Design complete courses using the Personalized Learning Model with its zones to develop intensive reading skills and other social, metacognitive and motivational ones in different educational stages. 
The Effectiveness of Personalized Learning Model in Developing Critical English Reading Skills among Preparatory Stage Pupils

Dr. Jehan El-Bassuony -Dr. Mahmoud Mohaseb - Marwa Moussa

References

A Guide for Implementing Personalized Student Learning Plan (PSLP) Program(2014). New Jersey Career Assistance Navigator Retrieved on December 25, 2017 from: https://www.state.nj.us/education/cte/pslp/PSLPGuide.pdf

Alyousef, H., (2005).Teaching Reading Comprehension to ESL/EFL Learners. The Reading Matrix 5 (2) .Retrieved on October 23, 2018from:

https://www.researchgate.net/publication/235771368_Teaching reading_comprehension to_ESLEFL_learners

Asztalos, R. (2014). The use of a wiki at a college in Hungary as a tool to enhance personal learning.; Proceedings of the 2014 Eurocall Conference, Groningen, The Netherlands: 18-22. doi:10.14705/rpnet.2014.000188, University of Groningen

Balikci, G. (2012).Taking a Critical Step on the Way to Critical Reading: Investigation into Critical Reading Discourse of Freshman Fle Students in an Advanced Reading and Writing Course, unpublished master's thesis, Middle East Technical University

Basham, J. Hall,T. , Carter, R., Jr, R.\& Stahl, W. (2016). An Operationalized Understanding of Personalized Learning Journal of Special Education Technology, 31(3) 126-136 DOI: 10.1177/0162643416660835 jst.sagepub.com, University of Kansas, Lawrence, KS, USA

Bray, B. \& McClaskey, K. (2013). A Step-By-Step Guide To Personalize Learning (International Society for Technology in Education), 40(7), 12-19. Retrieved on November 21, 2017from : https://files.eric.ed.gov/fulltext/EJ1015153.pdf

Dada , R. (2015). Personalized Learning: Perceptions of Curriculum Leaders and Mathematics Teachers in a Secondary School Classroom, unpublished master's thesis, Unitec Institute of Technology

Dag, F. \& Geçer, A. ( 2009 ).Relations between online learning and learning styles. World Conference on Educational Sciences. Procedia Social and Behavioral Sciences 1 (2009) 862-871, University of Kocaeli 41380, Turkey. Retrieved May 3, 2018 from: https://pdf.sciencedirectassets.com/277811/1-s2.0S1877042809X00029/1-s2.0-S187704280900158X/main.pdf?XAmz-Security-

Dinkins, T. (2017). Teacher's Perceptions of Implementing Personalized Learning in Urban Elementary School Classrooms, unpublished doctoral dissertation,Cardinal Stritch University 
The Effectiveness of Personalized Learning Model in Developing Critical English Reading Skills among Preparatory Stage Pupils

Dr. Jehan El-Bassuony -Dr. Mahmoud Mohaseb - Marwa Moussa

Gradu, P.\& Kuutila, N. (2016). Personalized Learning in English as

a Foreign Language Education , University of Jyväskylä.

Retrieved on November 5,2018 from:

https://jyx.jyu.fi/bitstream/handle/123456789/50973/URN:NBN:

fi:jyu-201608193829.pdf?sequence $=1$

Grant, P. \& Basye, D. (2014).Personalized A Guide for Engaging Students with Technology International Society for Technology in Education Eugene, Oregon, Washinton. Retrieved May19, 2019from:

https://www.intel.com/content/dam/www/public/us/en/documen ts/education/k12-personalized-learning-guidebook.pdf

Hanover Research (2012). Best Practices in Personalized Learning Environments (Grades 4 - 9). Retrieved on November 27, 2018 from: https://www.hanoverresearch.com/media/BestPractices-in-Personalized-Learning-Environments.pdf

Hartney, R. (2011). Investigating Reading Difficulties in English Second Language of Grade 3 Learners in One Primary School in The Khomas Education Region of Namibia, unpublished master's thesis, the University of Namibia. Tel:(0926461)2959411.Fax:(09 264 61)23136/Retrieved on July 7, 2018 from: https://www.academia.edu/27317689/

Hijazy,T. (2018).Personal Learning Environment. Retrieved on Dece mber25, 2018 from: http://drgawdat.edutechportal.net/archives/13548

Jenkins, A. \& Kelly, C. (2016). Biggest Challenges in Personalized Learning. Education Elements. Retrieved on June 27, 2018 from:

https://www.edelements.com/hubfs/Education_Elements_Bigge st_Challenges_in_Personalized_Learning_Analysis_2016.pdf

Koay, J. (2016). What Is Intensive Reading ? Retrieved on January3, 2020

from :https://www.edumaxi.com/what-is-intensive-reading/

Koller ,T. (2015).The Effect of Personalized Vocabulary Plans on Learner Autonomy in L2 Vocabulary Learning St., unpublished master thesis, Cloud State University

Redding, S. (2014). Personal Competencies in Personal Learning. Retrieved on March 11 from: http://www.adi.org/downloads/PC_forPL_\%20rev03.05.15.p $\underline{\text { df }}$

Shanahan, T. (2018). Comprehension Skills or Strategies: Is there a difference and does it matter? Retrieved on February 3, 2020 from:

https://www.readingrockets.org/blogs/shanahan- 
The Effectiveness of Personalized Learning Model in Developing Critical English Reading Skills among Preparatory Stage Pupils

Dr. Jehan El-Bassuony -Dr. Mahmoud Mohaseb - Marwa Moussa

literacy/comprehension-skills-or-strategies-there-differenceand-does-it-matter

Svenningsen, L. \& Pear, J. (2011). Effects of Computer-Aided Personalized System of Instruction in Developing Knowledge and Critical Thinking in Blended Learning Courses. The Behavor Analyst Today , 12( 1), ISSN: 1555-7855,University of Winnipeg \&University of Manitoba

Warfield, S. (2019). Read and Run: A Communicative Reading Activity. americanenglish.state.gov/english-teaching-forum. Retrieved onJuly21,2018from:

https://files.eric.ed.gov/fulltext/EJ1219076.pdf

West, D. (2011). Using Technology to Personalize Learning and Assess Students in Real-Time, Centre for Technology Innovation at Bookings. Retrieved May 17,2017 from: https://www.brookings.edu/wpcontent/uploads/2016/06/1006_personalize_learning_west.pdf

Wolf, M. (2010) .Innovate to Educate:system [Re] Design for Personalized Learning : A Report From The 2010 Symposium. Retrieved on October15,2019from:

https://dpi.wi.gov/sites/default/files/imce/cte/pdf/redesignperson allearning.pdf

Yu ku ,H. \& Sullivan, HJ. (2002). Student Performance and Attitudes Using Personalized Mathematics Instruction. ETR\&D, 50 (1), 21-34 . ISSN 1042-1629 .Retrieved on January21,2017 from: http://www.speakeasydesigns.com/SDSU/student/SAGE/comps prep/Student_Performance_and_Attitudes.pdf

Zou, D. \& Xie, H. (2018). Personalized Word-Learning based on Technique Feature Analysis and Learning Analytics. Educational Technology \& Society, 21 (2), 233-244.ISSN 1436-4522 (online) and 1176-3647 (print). Retrieved on October21,2017 from: https://pdfs.semanticscholar.org/4ee3/2dec6dbf3a96e83e3cf1e1a3f335 aefde164.pdf? ga $=2.24021821 .600680441 .1585385349$ $\underline{742093485.1575228195}$ 